\title{
The promotion of nutrition and food by the Ministry of Food in 1940-54
}

\section{By Patty Fisher, Blackmoor, Four Elms, Edenbridge, Kent and Freda Patton, 45 Ringrood Avenue, London $\mathrm{N}_{2}$}

When war broke out in 1939 it was realized that the restriction of food imports leading to food shortage, might cause malnutrition and poor health, as happened in $1914-18$.

The Ministry of Food was, therefore, set up to deal with the problems of providing a nutritionally adequate diet for everyone in Great Britain, i.e. for some fifty million people. Compared with World War I much better information was available about the energy and nutrient needs of people and the value of foods. $A$ national interest in food policy and health had begun in I934, when Sir John BoydOrr's survey of the National diet, Food, Health and Income showed that half of the people were not getting the Recommended Allowances which nutritionists thought desirable. At this time, too, a School Milk scheme was started, benefiting both children and farmers.

The policy-making committee at the Ministry was led by Sir Jack Drummond. It had direct access to the Minister and included nutritionists, economists, agriculturists, food scientists, and doctors. They decided to: ( 1 ) review all food supplies making a significant contribution to human needs for energy and nutrients as suggested by the National Research Council in USA; (2) make an informed selection of foods to import and grow at home; (3) organize a rationing scheme to ensure an equitable distribution of these foods to people, to maintain health and productivity; (4) promote a system of nutrition education at all levels to explain and motivate people to accept resulting changes in diet.

\section{Food supplies}

From $194^{\circ}$ onwards the Ministry of Food controlled all food supplies, food reserve stocks, and distribution. The Ministry was the sole importer and buyer of food produced by agriculturists, factories and farmers. Commodity divisions organized and controlled such foods as cereals, fats, milk and fat stock. Prices were fixed. Personnel came from firms, and food technology laboratories. The country had for some time relied largely on imported food and fodder, now home grown alternatives had to be considered. Imports of meat, poultry, cheese, tomatoes, vegetables and fruit were reduced and home production increased. Foods imported were also evaluated for shipping space. Milk and eggs were imported in dried form; meat and fish were imported without waste, i.e. boned and canned. Citrus fruits, as the chief source of vitamin $\mathrm{C}$, were largely replaced by home produced foods such as potatoes, cabbage, blackcurrants and rosehip syrup. Oranges were imported as concentrated juice and jelly. 
Wheat imports were reduced and more home-grown wheat sown. Flour milling was changed from $70 \%$ extraction (producing white flour) to $75 \%$ in $194 \mathrm{I}$, and $85 \%$ in 1942 , thus providing an extra 15 tons of flour per 100 tons of wheat. This National Flour was milled by special milling techniques to contain a higher level of wheat germ in the flour, thus giving higher values for B-vitamins and iron. Sugar beet produced in East Anglia replaced imports from the West Indies. Oils for margarine to replace butter and lard were imported, also soya-bean flour to increase and supplement protein supplies.

Enrichment of foods by added vitamins and minerals was first brought in in 194I. This policy ensured that people had adequate supplies of certain nutrients. Flour and consequently bread was enriched with thiamin, niacin, iron and calcium. To ensure that the calcium was fully absorbed and used, vitamin $D$ was added to margarine. Vitamin $A$ was also added, equivalent to the average amount in butter. These methods of improving the National diet are still in use today.

Farmers were given help, advice and incentives to produce more milk, eggs, cheese, bacon and poultry, as these have a better conversion ratio than meat. Imported fodder and the now scarce bran for feeding animals were replaced by home-grown crops and leys. They were also directed to produce more potatoes and oatmeal as these crops gave more food per acre than grain.

The general public were also encouraged to grow more vegetables, fruits and potatoes. The Ministry had regional and local committees to give expert information and to organize the use of gardens, both public and private, waste land, and allotments, for producing crops. The Allotment scheme was especially successful and the Russians sent over a team to gain information. Informed gardening advice was given by experts in the media and by leaflets and booklets. The Women's Institutes organized Produce Guilds who marketed their produce to the public.

\section{Distribution of food supplies}

To ensure good health the amounts of certain basic available foods to cover people's nutrient needs were calculated by Government scientists and statisticians. These were the Rations and everyone had a Ration Book, which entitled them to definite amounts of these basic foods, such as meat, bacon, cheese, fats, sugar, preserves and tea. Four types of Ration Books were issued: RBI for adults; RB2 for young children; $\mathbf{R B}_{4}$ for older children and $\mathrm{RB}_{3}$ for travellers. Young children got more milk, eggs, cheese and less meat and fats than adults. Vegetarians got extra cheese instead of meat (nutritionally a much better optionl).

In 1941, a Points scheme was introduced to deal with the equitable distribution of unrationed foods. These were foods in variable supply and demand, such as canned meats, fish, milk, fruits, syrup, treacle, peas and beans, dried fruit, pulses, rice and biscuits. Everyone had a Points allowance and could spend it according to taste and supplies - which varied according to enemy action. In 1942 a Personal Points scheme dealt with chocolate and confectionery and gave the same allowance to everyone. 


\section{Vulnerable groups}

For mothers, children, invalids, hospitals and schools a special distribution scheme was devised for such foods as milk, eggs, fish and oranges. In 1941, the Vitamin Welfare scheme was introduced to ensure that young children had enough vitamins $A, C$ and $D$. These nutrients might be poorly supplied due to lack of fruit, eggs and butter. They were provided by cod-liver oil (later by tablets of vitamins $A$ and D) and blackcurrant syrup or puree, orange juice and jelly. All were issued free, but later subject to payment.

\section{Catering}

Meals in restaurants and canteens were additional to the rations throughout the War, but supplies to catering establishments were rationed. Many Local Authorities set up British Restaurants which provided simple cheap meals and were a boon to many. School meals at a low price were organized in I $94^{\circ}$ to ensure that all children received enough foods for growth and health. The result of these plans was a National Diet based on ad lib. supplies of flour and bread, potatoes, oatmeal, vegetables and fruit (not oranges), plus rationed amounts of mill, cheese, margarine, butter, meat, bacon, tea, sugar and jam. The points allowance added foods for variety and taste. The fairness of the rationing scheme was accepted and appreciated by the public. It also encouraged people to try new foods, and make changes in their diet, since people usually had a proprietary interest in eating their own rations. Frauds and black marketing were, on the whole, at a low level.

\section{Promotion and application of the food policy to the public}

A scheme of practical nutrition and communication had to be devised to help people to accept these changes in their food habits and to make appetizing meals from food available. To promote and apply the food policy, the Ministry of Food had three divisions.

(1) The Scientific Advice Division provided the basic scientific facts of nutrition. Any material produced by the other two divisions had to be cleared by this division. It was reponsible for the nutrition education policy. It produced a monthly Nutrition bulletin and, later, the Manual of Nutrition, written in 1944 by Dr Magnus Pyke in characteristic style.

(2) Food Advice Division dealt with food preparation and the practical applications of the food policy. From their experimental kitchens, they produced attractive recipes, meals, diets, budgets, gave advice on cooking, prevention of waste, and preservation of home grown food. They had Food Advice Centres throughout the country.

(3) Public Relations Division were responsible for the production of posters, leaflets, films and broadcasts, using material provided by the other two divisions. They had close contact with the media.

At top level the food policy was communicated to key people by regular bulletins: (a) the Nutrition bulletins, sent monthly to doctors, nutritionists, lecturers and dieticians, explained and gave information about food and nutrition, 
(b) the Food Bulletin was sent monthly to caterers and domestic science staff to show the application to recipes, menus and (c) a weekly Ministry bulletin costing $4 \mathrm{~d}$ gave information about regulations and supplies.

The bulletins were supported by a team of expert lecturers who were briefed by the scientific advice division.

At public level Food Advice Centres arranged lectures for a variety of audiences. They gave talks at hospitals, colleges, schools, women's organizations and also used demonstration vans, well-equipped for food preparation, to give talks to audiences in market places. They co-operated with women's organizations in the Food Leader scheme.

They distributed the attractive leaflets for people to take home and use. These leaflets were of six main types. (I) How to choose foods and plan meals for situations, and special groups, e.g. packed meals, invalids, young children and active men. (2) Teaching housewives how to cook, giving basic recipes and methods, using foods available, e.g. pastry-making, cooking green vegetables and shallow frying. (3) Simple nutrition education, with foods grouped according to function e.g. foods for energy, growth, and 'protection'. This last category was a useful term at the time, when the specific functions of vitamins and minerals were less well-known. (4) How to use unusual and special foods, e.g. dried egg, milk, salt cod and dried fish. (5) Special war-time recipes, for special occasions, seasonal recipes. (6) Advice on food management and prevention of waste, e.g. fats, meat, bread, sugar. The high level in these leaflets of accurate information and presentation is still notable, and much better than other government departments often achieved. Their style and content were copied in other countries, such as Czechoslovakia, to help with food shortages and nutrition education, after the war.

To ensure that food advice reached everyone, the media gave vital help. Useful official advice was given in the Press in daily papers and magazines. In cinemas, a one minute Food Flash about the use of a food and its value had impact. On radio Dr Charles Hill, 'The Radio Doctor', in a series called 'Wise eating in Wartime' popularized the concept that good health depends on good food choice and habits. Dr Louise Davies gave advice on shopping and meals daily at 7.30 a.m.

\section{What were the results of these fourteen years of the work of the Ministry of Food?}

They were first noted by international members of the Nutrition Society when they came to the meeting at the London School of Tropical Hygiene in 1946. Fellow members, showing the severe strain they had endured during the war, were amazed at the improvement in health of the British, in spite of food shortages and air raids; especially they said in the health of the children and infants. For the first time in our history everyone in Britain, rich and poor, had a nutritionally adequate diet and a Food Policy controlled by nutrition experts instead of politicians and financial interests at home and abroad. For the first time, a reliable, practical scheme of nutrition education was promoted at all levels to the people.

Food, recipes and meals were a major topic of conversation throughout the war. 
Thanks to the work of the skilled staff who applied and promoted the food policy, the talk was better informed than ever before. Food choice and standards of home cooking improved rapidly with such good, unified promotion.

In 1904, poor food choice and home cookery was seen as contributing to the poor health and physique of soldiers called up for the Boer War. To remedy this situation, domestic science teaching was promoted in schools, but success was only partial. In $194^{\circ}$ the Ministry of Food, with superior skills of nutrition know-why, cookery know-how, plus expert public relations' techniques of communication to people at all levels, gave educationalists, home economics staff, journalists and caterers a strong lead in nutrition education and food preparation. They responded with enthusiasm to its clear guidance and used the information and applications in their work. The results of the Ministry's policy were shown in statistics of improvements in health, physique, dental status, sickness and mortality rates.

When the Ministry of Food was disbanded in 1954 (thus saving $£ 3000000$ of public expenditure) commercial interests adopted their successful approach, but Government control was lost and motivation changed. Lacking the reliable, coordinated, unified policy, nutrition education became a 'free-for-all', with too many diverse methods and loss of impact.

The ramifications of the Ministry's work in controlling all food supplies in Britain are too great even to be outlined here. A short account of the whole picture is given in How Britain was fed in Wartime (HMSO, 1946). The Ministry's experiences and organization are enlightening. In this instance only the food policy and promotion of nutrition is described. Some members of the Society may not have seen this material. Much of it has already been destroyed, so this is not a complete collection. This brief account it is hoped, may interest people to read more about the Ministry of Food and to look at the collection in the Imperial War Museum.

\section{Conclusion}

Could the experiences of the Ministry of Food help people now, to cope with food shortages and poor food choice resulting from a lack of nutrition knowledge and from to-day's high prices?

Would a National Nutrition policy, based on a core of low priced, high value foods, available to all as 'Rations for Health', and supported by a National scheme for nutrition education, help the Country today?

\section{REFERENCES FOR FURTHER READING}

The Englishman's Food. By Drummond and Wilbraham. (1958) edition p. 448 onwards.

Nutrition in the Community. By Maclaren (1976). Chapter 30. Nutrition in the U.K. By Hollingsworth and Patton.

How Britain was fed in Wartime. Ministry of Food (1946). London: HM Stationery Office.

The work of the Ministry of Food. By R. J. Hammond.

Food I Growth of policy.

Food 2 Growth of policy.

Food 3 Studies in administration and control.

Problems of Social Policy. By Richard Titmuss (1950). HM Stationery Office. 